\title{
Tracing the Traditional Contents and Forms in Contemporary Nepali Paintings
}

\author{
Yam Prasad Sharma*
}

\begin{abstract}
Contemporary Nepali paintings integrate contents and forms of early Nepali arts using impressionist, expressionist and surrealist techniques from western arts. The artworks have intertextuality since they share western art trends and Nepali artistic traditions. These works decontextualize the shared contents and forms and recontextualize them in the contemporary Nepali context through appropriation. The artworks use the same thing for different purposesat different times and places. Contemporary Nepali paintings like Laya Mainali's Saswat, Yogendra Dangol's Vajra Mandala, Buddhi Thapa's Cosmic Wave, Shankar Nath Rimal's Dance of Shiva-Shakti and Puran Khadka's The Form to the Formless have integrated the icons, images and symbols of the Hindu and the Buddhist mythologies, the contents of traditional Nepali paintings and sculptures. The figures of gods and goddesses, their attributes and associated symbols have been presented in traditional Nepali arts in reference to the related myths. Structure of paubha and mandala, decorative patterns, two-dimensional colors and distinct contours are the formal qualities of these traditional artworks. These forms and contents of traditional arts have been reintegrated in contemporary Nepali paintings exploiting western techniques like fragmented lines, rough texture, distorted colors and figures, and dreamlike images and symbols. These playful western art forms facilitated Nepali artists to express their personal feelings, emotions, experiences and imagination in response to contemporary context of Nepal. These artworks present the cultural dialogue, interaction, and coexistence of traditional art forms and contents, and western techniques.
\end{abstract}

Keywords: Traditional Nepali arts, western techniques, contemporary Nepali paintings, referential, ambivalent, intertextual

\section{Introduction}

${ }^{*}$ Mr. Sharma has been working as Lecturer in English at Fine Arts Campus, Tribhuvan University, Nepal. 
Contemporary Nepali paintings have integrated the images, symbols, ideas and forms of traditional Nepali arts using western techniques to respond to the modern context. Western techniques have been shared from impressionist, expressionist and surrealist paintings. Impressionists capture the impression of the thing at a particular transitory moment of the day (Gilbert 1998, p.459). The image of the thing can change due to the change in the intensity of light and the change in atmosphere. The same thing can appear different at different times in the same day. The picture of the same thing can be other when painted in the morning, afternoon and evening. To capture the particular moment, the artist paints hurriedly. Otherwise, there can be a change in light and atmosphere. When the artists paint quickly, the picture appears rough. As a result, there is a distance between the painted pictures and the real objects. Expressionists distort or alter the colors and images to express the inner feeling and emotions (Canady 1959). The colors and images in the paintings are unconventional and unusual. Surrealists juxtaposed the contrary images with the free association as in dreams (Gilbert 1998). The images are melting and changing shapes. The images and forms are considered to have emerged driven by the unconscious mind. The artists also emphasize on artistic automatism. Contemporary Nepali artists decontextualize these art techniques from western art and recontextualize the shared practices in Nepali paintings. The artists have used same methods for the different purposes, and this process is called appropriation.

In the domain of Nepali painting, features of contemporary art appeared after the end of the Rana regime in 1950 due to the western influences and the cross flow of artists and people within the country and beyond. Nepali artists got exposure to various contemporary western art forms and style. The artists directly encountered western art forms and techniques. Despite the influence of the west, Nepali artists integrated traditional icons, images and symbols in their artworks. One visual text has connected to other visual texts having intertextuality. The artists have created artworks in reference to other artworks (Barthes 1992). Such interconnection of different artworks is called intertextuality. Before interpreting and discussing contemporary Nepali paintings in relation to its tradition, it would be worth mentioning the essential features of traditional Nepali arts. Traditional Nepali arts are referential, for they represent the images, characters and events from myths. They are symbolic, magical and didactic. The artists created these works mainly for the religious purposes like worshipping, praying and meditating.

Traditional paintings are in the form of manuscript illuminations, paubhas and mandalas. These paintings depict the Buddhist and Hindu divinities along with associated ideas. The images and symbols in arts have been connected to myths and rituals (Ray 1967).There is the coexistence of art, life and mythology. People worship 
these arts as images and icons of gods and goddesses. Percy Brown (1912) traces the magical and didactic aspects of traditional Nepali arts:"Nepalese artist either elevates the observer by the transcendental nature of his celestial conceptions or terrorizes him into docility by his suggestions of purgatory" (p.130). The works are worshipped rather than admired. These traditional arts were an integral part of religious and cultural rituals.

Prajnaparamita manuscript dated 1054presents various scenes from Buddha's life, and various bodhisattvas. Scenes from Buddha's life include Buddha's nativity and meditation under the bodhi tree to achieve nirvana. Hindu manuscript illuminations present the characters, events and symbols of Hindu myths like Bhagavata Mahapurana and Shiva Purana.

The paubha paintings attempt to resolve the dualities between the individual self and cosmic being. In the paubha, principal deity resides at the center, and subsidiary deities and other images are around the central figure. Pratapaditya Pal (1978) mentions the stylistic features of paubha painting: "Paubhas are essentially religious icons, the artist was bound by certain immutable iconographic rules and aesthetic canons which had been established by theological precepts and long-standing tradition" (p.65). Some paubha paintings are created in the structure of themandala. Such mandalas are magical and symbolic, and used as the yantra (instrument) for meditation (Sharma, 2014). The principal deity resides at the center within circles. The design and the images take the individual to the center of the composition where one is supposed to unite with the central divinity. About the structure and features of mandala, Stella Kramrisch (1964) further explains:

Mandalas are visual supports of concentration and mediation, ritual aids on the way toward the center of the cosmos and self. Cosmos and self coincide in the image of the central and main divinity of the mandala. This divinity resides in principle, in an eight- petaled lotus. (p.44)

Shivalinga, lotus, vajra and meditating figures are recurrent images in both paintings and sculptures. These traditional forms and contents have been integrated in modern Nepali works exploiting western techniques of art. The statement has been supported by analyzing and interpreting contemporary Nepali paintings like Saswat, Vajra Mandala, Cosmic Wave, Dance of Shiva-Shakti and The Form to the Formlessusing theoretical tool of intertextuality.

\section{Research methodology}

This research has used qualitative approach to analyze and interpret the paintings since art appreciation, criticism and interpretation are highly affected by critics' subjective perceptions and responses. The area of research is contemporary Nepali 
paintings. The theory related to intertextuality and interconnection of arts has been used as a tool for analysis and interpretation of paintings in the research area. This paper has used secondary sources like books, magazine articles, journal articles and exhibition catalogs of artworks to introduce the research area and develop the theoretical tools. The primary sources are the paintings that have been analyzed and interpreted to support the statement. The researcher visited art galleries and artists' studios to locate the artworks and interview with the artists.

\section{Connection of a work of art to the other}

In contemporary Nepali paintings, there is the coexistence of both traditional Nepali art and western techniques. Before tracing these features in the artworks, it would be better to throw light on how different art forms and cultures are interconnected. This section attempts to make a theoretical base on how different artworks are linked and meanings are constructed. When two cultures and art forms encounter to each other, they face contradictions and differentiations which give way to dialogue and interaction in the process of reconstructing identity.This is a process of "making local sense of the collision" (Lechner and Boli 2000, p.320). Being located at the ambivalent space, the artists reread both global and local images. The native artists appropriate alien art forms and techniques. In the process of appropriation, the artists used the shared techniques for different purposes in other contexts. Such artworks incorporate the images of traditional arts with different significance in different contexts.

According to Homi K. Bhabha (1995), artworks are constructed in "contradictory and ambivalent space", and the meanings of art works are continuously constructed and reconstructed making sense of the available cultural forms (208). Similarly, Edward Said (1994) states that artworks are the matters of "appropriations, common experiences and interdependencies" of cultures (pp. 261-62).

Roland Barthes (1992) argues that a work of art is a "multi-dimensional space" where several art forms are "married and contested"; a text consists of "a fabric of quotations, resulting from a thousand sources of culture" (1132). A work of art interconnects to many other artworks. Earlier arts influence the arts of contemporary time. A piece of art is a response to another composition. To carve one's space, new artist misinterprets the earlier artists' works (Bloom 1988). According to Umberto Eco (1988), "works are created by works, texts are created by texts" (447). In this sense, artworks are always intertextual and interconnected to other works.

John Carlos Rowe (1992) states that contemporary arts revitalize traditional art forms with intertextuality. The works present the "creative appropriation of tradition" (Delanty 2000, p. 154). There is the play of historical allusion and stylistic pastiche 
(Jameson 1988).With the arrival of different cultural images in a particular context, the meaning is constructed provisionally and always remains in process of becoming (Hall1997).In the same manner, contemporary Nepali paintings are interconnected to traditional art forms and contents along with western techniques of art, and their significances are plural. In the forthcoming section, the analysis and interpretation of the artworks has traced these features.

\section{Interpretation and discussion of contemporary Nepali paintings}

Contemporary Nepali paintings are the mélange of subject matters and forms of early Nepali arts along with western techniques and forms. Traditional icons, images and symbols have been integrated through western art techniques of the twentieth century. Different cross-currents encounter and interact at ambivalent space creating open-ended art forms. The artworks present heterogeneous images and forms being inter-twined. In this sense, there is plurality in their significances. The meanings of these art forms are not fixed and specific but provisional and ever-shifting.

Laya Mainali's painting Saswat represents the entire universe within and around the Shivalingaby exploiting surrealist art techniques. The image of Shivalinga is one of the famous icons of traditional Nepali arts. The circular disc which the Shivalinga has penetrated, and the Shivalinga itself are altered. The surface of the circular disk is not even as we see it in the Shivalinga that one finds in Hindu temples. The rough texture brings up other pictures in our imagination. The images of hills, roads, the bank of the river, and grassy land appear within the uneven surface. Although the pictures seem abstract, as we view closely, they vaguely resemble the figures of the Himalayas, hills, fields, houses, rivers, ocean, boats and human beings. The background of the Shivalinga is also unconventional because it is crowded with strange abstract colors and shapes. The combination of some of the images is surrealist. The flowers on the circular disk do not seem to be flowers offered to the Shivalinga while worshipping but the flowers on plants that grow on the disk. The appearance of the images like hills, rivers and ocean in the Shivalinga, as mentioned above, are contrary because traditionally, Shivalinga appears in particular places of the world, not the world within theShivalinga.The Shivalinga seems to contain the entire universe within itself. The image symbolizes the union of the Shiva and Shakti. Lydia Aran (1978) writes about Shivalinga:

Shiva cult in Nepal comes in the form of Lingam (Phallus), which was the early form of

Shiva icon. The Lingam is roughly cylindrical in shape, standing upright on its narrow end and rounded at the top. It usually stands on a flat rimmed disc called yoni being possibly the female symbol. There is an indentation on one side of the yoni. (p.78) 
All the things in the world appear to exist within Shivalinga. The distance between the individual sadhaka and the external world has vanished. When the sadhaka identifies himself with Shivalinga, he realizes the entire world within. The appearance of various images within and around the Shivalinga represents the enlightenment who finds the cosmos within himself. Mainali's Saswat depicts the whole universe within and around the Shivalinga. Though the artist uses the surrealist technique, the artwork links itself to the tradition of Nepali art. Abhi Subedi (1992) states: "The westernization of the Nepali art does not mean the loss or the complete rejection of the traditions. Nepali identity of the artist in this country should be sought in their own cultural and folk environments" (p.123). Shivalinga is one of the frequent icons in traditional Nepali paintings and sculptures (Sharma, 2014). Furthermore, the theme of union between individual self and the cosmic being are also the themes of many traditional Nepali mandalas.

Yogendra Dangol's surrealist painting Vajra Mandala integrates the mandala, a form of traditional Nepali art, and tries to resolve the dualities of the inner self and the external world. Vajra is the yantra (instrument) held by different Buddhist deities in the traditional Nepali arts. In traditional mandalas, the figure of central god who holds the vajra is more important than the vajra itself. It is one of the many instruments of the deity. Obviously, the size of the divinity is more significant than the instrument he holds. But in Yogendra Dangol's Vajra Mandala, the artist subverts the structure of traditional mandalas by making the vajra as big as the canvas itself, symbolically encompassing the entire universe, and depicting the divinity in tiny size within the vajra at the center. Such condensation and displacement are the techniques of surrealism. Vajra is the symbol of the union of prakriti and purusa.Vajra, the symbol of purusa or phallus, penetrates open lotus, the symbol of prakriti or yoni, suggesting that nirvana is possible only through the union of prakriti and purusa. In this painting, at the center of the open lotus, where vajra intersects, a Buddhist divinity appears in small size, suggesting the realization of the nirvana. The artwork aestheticizes the tabooed concept, like the union of yoni and phallus.

The concept of the union of the prakriti and purusa may be associated to the union of individual self with cosmic being. According to Buddhist mythology, prakriti is the symbol of worldly elements, including the individuals that get power through the union with purusa. Then the individual self creates a harmonious relationship with cosmic being by achieving the nirvana. The association of lotus and vajra presents the worldly thing's union with celestial being. The images of mountain, forest, lakes, and some other abstract images represent the innumerable things of the world that appear around and within the vajra. Julia Hegewald (1996) comments that the artist considers tradition not as something static, but as a continuously changing and progressing 
movement, out of which he has emerged; he is working on developing the ancient artistic heritage influenced by new and foreign ideas (p.100). The painting shares the content and form of traditional mandala painting. The work is rooted in the tradition, and at the same time, goes beyond the convention. The composition revisits early Nepali artworks with a new form.

Radheshyam Mulmi's surrealist painting Untitled presents Buddha's teachings, one of the themes of Buddhist manuscript paintings with objective correlative of colors, visual images, and symbols. The principal figure of the picture is meditating Buddha on the lotus seat. Buddha's body and the edges of his garment are connected to the lotus petals, and they merge and melt into each other as in a dream. There is no distinct line between his body and lotus. Similarly, lotus petals melt into the water below and a female figure on the right side.

The fish seem to be dissolving in water. The birds' feathers appear to be melting and moving spontaneously into the body of the female figure. Because of the melting shapes and rhythmic colors, the boundary between sky, land and ocean has been blurred, suggesting playfulness and plurality. The fish goes above the water and reaches the side of Buddha's seat. Both fish and birds are flowing together with musical movement. The figures of folded hands appear bigger than meditating Buddha. Though the artwork juxtaposes contrary images as in a dream, all the living beings exist in harmony suggested by the rhythmic lines, colors and shapes. Older woman at the top is helping the younger one below. The painting presents Buddha's teachings after his enlightenment like one should have compassion, kindness and love towards fellow beings. Such relationships and attitudes help human beings to become real humans and create a harmonious society with peace and spiritual prosperity.

The folded hands at the back of the meditating Buddha present the artist's attitude. He respects Buddha for his love for all living things. The figure of meditating Buddha refers back to Prajnaparamita manuscript illuminations. The visual compositions of this manuscript represent the events from Buddha's life, including his meditation, achievement of enlightenment and his preaching. The artist's approach towards western forms and techniques has been his "strength," and he appears to combine "tradition with modernity" through stylistic experiments (Subedi 2005,p.117). In the painting Cosmic Wave, Buddhi Thapa presents cosmic harmony, one of the themes of traditional paubha paintings using the expressionist technique. The use of a wide range of colors symbolizes the existence of almost all the items of the world. Instead of the figures of the things in the world, the artist includes only their colors to represent them through metonymy. He takes a part from the whole thing. Then he depicts his vision of cosmic harmony using rhythmic waves. Most of the images of waves are unconventional although few colors resemble the waves in the ocean. The 
waves are in yellow, brown, red, green, white, blue, and other variations of these colors. The objective of altering the colors in the wave is to integrate the innumerable colors found in the different things of the world. He changes the images of various things into the form of waves. These are all-inclusive waves as the universe is all-inclusive. The artist strikes a balance between realistic and expressionist techniques in the sense that some waves are objective representations of the real waves whereas others are arbitrary and unconventional.

The artist shares the Hindu mythological belief of the omnipresence of cosmic power or prabrahma in everything, and that remains in perpetual harmony. According to Bhagavata Gita, God created all the things in the universe, and everything moves and grows due to the power of God. Since everything happens because of almighty, they have an underlined purpose. The universe is harmonious and in the constant rhythm, which can be felt and realized only through meditation. As one reaches the state of nirvana, there is no conflict in the self and cosmic being. There is no clash between the individual and the other things around. The person is supposed to find the presence of the same spirit in all things. Buddhi Thapa (2006) himself states in the exhibition catalog of his artworks about his outlook toward spirituality and his motive for creating a painting:

My desire was not just to understand the physical arrangements of nature but the abstract expansion of the cosmos surrounded by the realm of my curiosity. I was able to comfort this curiosity by going through various books on Hindu religion and mythology, Christian \& Muslim philosophical \& spiritual beliefs. Questions of science $\&$ its calculative verifications of existential phenomena also grew larger in my mind. Books on meditation helped me to understand my discovery of the existential mysticism. (Exhibition catalog)

As the movement of waves in the painting, the universe and its constituents emerge, develop and dissolve within cosmic being in a rhythmic manner. In his creation, the artist presupposes the existence of world spirit. K. L. Kaul (2006) comments that his artworks integrate several ideas and elements connected with cosmic lore using abstract images. One can find such contents in traditional Nepali paintings like manuscript illuminations, paubhas and mandalas. Similarly, the content of Hindu mythology comes into dialogue with contemporary art. The artist appropriates the western technique of expressionism to depict the peace, harmony and coexistence in the cosmos.

Shankar Nath Rimal's expressionist painting Dance of Shiva-Shaktialso depicts the theme of cosmic harmony by integrating the content of the traditional Nepali paubha painting, Nritesvara. The traditional art and western technique are interconnected to each other, having intertextuality. Nritesvara presents the erotic 
union of Shiva and Shakti, and their rhythmic dance at the center of the paubha painting, and other minor deities are around the central divinity. The gods and goddesses are the representations of the mythical characters. They have many hands with weapons and other symbolic images. The artist, in the artwork, Dance of ShivaShakti, takes the content of their dance, and their union is implied but not presented overtly in the state of the erotic union. The artist does not depict the deities with their many hands. The figures of Shiva and Shakti occupy the entire canvas omitting minor deities. Rimal leaves every detail of the traditional art form. He takes the part of the early work and presents it in the expressionist form. Rimal's work is more anthropomorphic than the early painting, for he presents Shiva and Shakti in human form, leaving the mystical many hands, weapons and symbols. Dance of Shiva-Shakti appropriates the content of Nritesvara painting. This artwork creatively shares the tradition using the western techniques.

According to Hindu mythological beliefs, Shiva represents purusaor the male principle whereas Shakti represents prakriti or the female principle. The union of these two forces is supposed to create cosmic concord with continuity of life and world. When an individual sadhakaor the practitioner of yoga as purusa unties oneself with prakriti through meditation, s/he is supposed to gain the status of Shiva, the almighty himself. The person finds himself as Shiva united with Shakti, and dancing in cosmic rhythm. The obstacles between the individual self and the world vanish because he finds himself in everything of the world and the whole universe within himself. This is the transcendental experience at the time of enlightenment. In the painting Dance of ShivaShakti, the artist presents the same theme with the expressionist technique. The artist alters the images of dancing figures. Their gender is indistinct, suggesting the absence of duality after the union of prakriti and purusa. Himalayan mountain, the abode of Shiva and Shakti, appears small in the background. All the things in the world become integral parts of the dancing couple. The presentation of the pervasive dancing figures of Shiva and Shakti suggests that the universe is within the bodies of the divinities. Western artists used the expressionist technique to explore the tragic subject matters but Rimal's painting exploited the same method to present cosmic harmony. Hence, the artist has creatively applied the western approach to integrate one of the essential issues of the early Nepali paintings.

Puran Khadka's painting The Form to the Formless attempts to present the hidden aspects of human life and the world through abstract composition. He tries to present the experiences that our sense organs are unable to perceive and feel. The quest for invisible power beyond tangible reality is one of the themes of traditional Nepali arts. He explores this theme using lines, colors and unusual abstract shapes in his work. The shapes do not represent recognizable things and characters. The viewers can see the 
new shapes and curves that are unlikely to be found in the externally visible and tangible world. Nevertheless, they are likely to participate and flow in the rhythmic movement of colors and lines. The more one goes ahead the more one finds new aesthetic shapes. The journey goes on and on. The abstract composition creates a meditative mood in the viewers.

General belief is that the world of tangible reality, and the experience perceived through senses are most important. But Khadka's painting goes beyond this reality, and brings such questions: who created the universe? How was it created? How do the plants grow? How do the animals move? What drives them forward? How one day the same animal becomes inanimate? The work is a visual exploration of the underlined essence that governs life and the world. The artist himself states that his paintings represent his quest of the self in relation to the universe (Khadka 2014). According to Uttam Nepali (1998), Puran Khadka's painting offers spiritual solace to the viewers. Traditional Nepali paintings also present such theme. The composition shares the western technique of abstractionism and explores the Hindu myth regarding the soul. Western style and the content of conventional Nepali art coexist in harmony on the same canvas. Saroj Bajracharya (2003) argues that the painting shares the values that our tradition had to offer us with a blend of fresh ideas. The use of western techniques as tools in contemporary arts revitalizes the early art forms. Contemporary Nepali artists have incorporated traditional art forms in their artworks to express their imagination.

\section{Conclusion}

Contemporary Nepali artists have been exposed to different western art techniques like expressionism's distorted colors and figures, surrealism's dreamlike images, and abstractionism's forms. These western art techniques helped the Nepali artists to break away from referential representations providing them the opportunity to express their imagination and personal feelings in the artworks. Simultaneously, the contents and forms of conventional Nepali arts come forth as their artistic root. Then referential traditional art forms and plural and subjective western art forms interacted and cooperated through cultural dialogue. The artworks have an ambivalent attitude toward both tradition and modernity. The artists have decontextualized the shared forms and contents, again recontextualized, and appropriated them in their compositions. The artworks have reformulated and revitalized the structures of the mandala, the icon of Shivalinga, the images of divinities, and cultural symbols using western techniques as tools. Although the artists shared modern art techniques, they have connected their creations to their cultural roots. Such an approach may be useful in other genres of art, and social practices as well. These issues can be the subject matter of another research. 


\section{References}

Aran, L. (1978). The art of Nepal: A guide to the masterpieces of sculptures, painting and woodcarving. Kathmandu: Sahayogi.

Bajracharya, S. (2003). Nearness of difference: Sikkim art tour. Exhibition catalog. Kathmandu: Zero Century Nepal.

Barthes, R. (1992). The death of the author. Critical theory since Plato. Ed. Hazard Adams. New York: Harcourt Brace Jovanovich College, 1130-33.

Bhabha, H. K. (1995). Cultural diversity and cultural differences. The post-colonial study reader. Eds. Bill Ashcroft, Gareth Griffiths and Helen Tiffin. London: Routledge, 206-209.

Bloom, H. (1988). Poetic origins and final phases. Modern criticism and theory. Ed. David Lodge. London: Longman, 241-252.

Brown, P. (1912) Picturesque Nepal. London: Adam and Charles Black.

Canady, J. (1959). Mainstreams of modern art. New York: Hult, Rinehart and Winston.

Delanty, G. (2000). Modernity and postmodernity: Knowledge, power and the self. London: SAGE.

Eco, U. (1988). Casablanca: Cult movies and intertextual collage. Modern criticism and theory. Ed. David Lodge. London: Longman, 446-55.

Gilbert, R. (1998). Living with art. Boston: McGraw-Hill.

Hall, S. (1997). Cultural identity and diaspora. Contemporary postcolonial theory: A reader. Ed. Padmini Mongia. Delhi: Oxford UP, 110-121.

Hegewald, J. (1996). Our studio is nature- the work of the new art circle in Nepal. Journal of the Nepal Research Centre. Vol. x.: 95-101.

Jameson, F. (1988). The politics of theory: Ideological positions in postmodernism debate. Modern criticism and theory. Ed. David Lodge. London: Longman, 37383.

Kaul, K. L. (2006). The exhibition catalog of Buddhi Thapa's contemporary paintings, Kathmandu.

Khadka, P. (2001). "Puran Khadka: Artist, Painter." Unpublished essay. Artist's studio in Nepal Association of Fine Arts (NAFA), Kathmandu.

Khadka, P. (2014, December 12). Interview. Kathmandu.

Kramrisch, S. (1964). The art of Nepal. New York: Asia House Gallery.

Lechner, F. J. and J. Boli (2000). eds. The globalization reader. Massachusetts: Blackwell.

Nepali, U. (1998). Exhibition catalogue of Puran Khadka's paintings, Kathmandu. 
Pal, P. (1978). The arts of Nepal part II. Leiden: Tuta Sub Aegide Allas.

Ray, A. (1967). A note on the character of the plastic art of Nepal." Journal of the Tribhuvan University 3.2: 10-15.

Rowe, J. C. (1992). Postmodernist studies. Redrawing the boundaries. Eds. Stephen Greenblatt and Giles Gunn. New York: The Modern Language Association of America, 179-280.

Said, E. (1994). Culture and imperialism. London: Vintage.

Sharma, Y. P. (2014). Nepali painting: A critical analysis. Kathmandu: Nepal Academy of Fine Arts (NAFA).

Sharma, Y. P. (2019). Contemporary Nepali paintings: A distinct cluster. Kathmandu: Society of Modern Artists (SOMA).

Subedi, A. (1992). Nepali art: Nepali utopia. Contributions to Nepalese Studies 22.2: 113-130.

Subedi, A. (2005, Feb). Modern Nepali art: An overview. Jamini, 108-117.

Thapa, B. (2006). The exhibition catalog of Buddhi Thapa's contemporary paintings, Kathmandu. 